objective test, but the difficulty here is that asthmatics usually take a variety of drugs, which may be bronchodilators, antibiotics, or sedatives. Since most patients do not know what purpose their various medicines serve, no attempt was made to discriminate between the number of tablets of each variety, though as a test of progress only the bronchodilators would be expected to refiect fluctuations in the severity of asthma. The number of occasions on which an aerosol was used is probably a more reliable criterion of progress.

Because of these difficulties in setting up objective criteria of progress, the expiratory peak flow is the only quantitative observation free of bias in this study. The limitations of making this measurement only once a month were appreciated, but the difficulties of repeating it more frequently proved to be insuperable. The variability of observations in asthmatics from one day to another is well known, and for this reason no attempt was made to analyse in any detail the month-by-month changes in peak flow. A simple method of recording the trend of these six measurements as improvement or deterioration was thought to be the most that could be extracted from these data. The uncertainty of the observation is not presented in an attempt to throw doubt on the negative result of this trial, but merely to stress a problem inherent in the study of a disease in which the state of the patient varies from day to day and in which most of the observations reflecting these changes cannot be translated into objective measurements.

Another source of uncertainty is that house dust extract cannot be standardized by chemical tests or biological assay, so that its composition may vary from one batch to another. Which of its many components causes asthma has not been established, and it is possible that the material used in this study was deficient in extract of mites or some other relevant antigen. This doubt applies with equal force to other commercially available house dust extracts and will not be resolved until these antigens are identified.

Patients who were given advice on house dust control in their homes did not fare any better than those who did not receive such advice. Possible reasons are either that the amount of house dust is immaterial, or that the patients did not carry out their instructions, or that these instructions were not effective in reducing the dust below the critical level. Nothing was known about the habitat of the house dust mite at the time, and the possible importance of mattress dust was therefore not appreciated (Cunnington, 1967). It was also found in retrospect that some patients who had not been explicitly advised were nevertheless exercising some control over house dust, acting on common sense or on advice received from sources outside this study.

An observation not foreseen in the design of the study is that physicians vary in their clinical judgement of what they will accept as pure house dust allergy. The criteria of diagnosis were closely defined in the protocol, but what eventually decided whether the history given by patients incriminated house dust alone or other antigens as well was the opinion of the physician. When the reason for the large differences in the number of entries was discussed it became clear that some physicians regard pure house dust allergy as rare and think that it is nearly always accompanied by allergies to other inhaled antigens, particularly pollen, while others readily diagnose pure house dust allergy among their patients.

An interesting sidelight on the attitude of patients to clinical trials is that so many of them were willing to take part in this study. The details of the treatment were explained with scrupulous fairness so that each patient clearly understood that the 15 injections he was to receive were at best of an extract of doubtful efficacy and at worst of a substance unlikely to have any therapeutic value at all. In spite of this explanation only 20 of the 116 patients approached declined to take part. This is a suitable place to acknowledge the Research Committee's indebtedness to those patients who accepted the inconvenience and discomfort of this investigation.

The Research Committee wishes to thank Dr. M. Pike, of the Statistical Unit of the Medical Research Council, for his help in planning the trial.

The Committee alse wishes to express its indebtedness to Mes;srs. Bencard and, in particular, Dr. F. H. Milner, director of the Allergy Unit, for their generosity in supplying free of charge the house; dust extract and control preparation used in the trial.

REFERENCES

Bruun, E. (1949). Acta allerg. (Kbh.), 2, 122.

Cunnington, A. M. (1967). Acta allerg. (Kbh.), 22, 415. McAllen, M. K. (1961). Thorax, 16, 30.

\title{
Effect of Oral Contraceptives on Depressive Mood Changes and on Endometrial Monoamine Oxidase and Phosphatases
}

\author{
ELLEN C. G. GRANT,* M.B., CH.B., D.oBST.R.C.O.G. ; JOHN PRYSE-DAYIES, † M.D., M.C.PATH.
}

Brit. med. F., 1968, 3, 777-780

Summary : Significant variations in the incidence of depression and loss of libido were found with the various types of oral contraceptives. The highest incidence occurred with strongly progestogenic compounds (especially with those containing a small amount of oestrogen) which have high monoamine oxidase activity for most of the cycle. The lowest incidence was found with the strongly oestrogenic sequential regimens which have weak monoamine oxidase activity for most of the cycle.

\footnotetext{
- Council for the Investigation of Fertility Control, 27-35 Mortimes Street, London W.1. + Bernhard Baron Memorial Research Laboratories, Queen Charlotte's
Maternity Hospital, London W.6.
}

\section{Introduction}

Mears and Grant (1962), Pullen (1962), and Goldzieher et al. (1962) reported that premenstrual tension improved in women taking progestogenic/oestrogenic oral contraceptives. Mears and Grant (1962) also reported changes in libido which they suggested might be due to psychological factors. However, it became clear that depressive changes were more troublesome with some products than with others. It was therefore decided to study the effect of the various types of oral contraceptives on the histochemistry of a selected group of enzymes in the endometrium. Monoamine oxidase, which was also measured biochemically in some cases, was of special interest because monoamine oxidase inhibitors are used for treating depressive states. Alkaline and acid phosphatase were chosen as marked 
enzymes with known variations in the normal cycle. McKay et al. (1956) described a decrease in alkaline and an increase in acid phosphatase during the late secretory phase. Cohen et al. (1964) demonstrated an alteration in the staining for endometrial monoamine oxidase in the latter part of the menstrual cycle, and Southgate et al. (1967) showed that in vitro there may be as much as a tenfold increase in biochemical activity of monoamine oxidase in the late secretory phase of the normal cycle.

\section{Method}

Full clinical histories, including details of premenstrual tension and previous mental illnesses, were obtained from volunteers attending the central clinic of the Council for the Investigation of Fertility Control. A total of 797 women received one or more of 34 oral contraceptives (Tables I and II), giving a treatment experience of 1,217 women. The incidence of depression, loss of libido, tiredness, and irritability occurring with the various formulations was observed over six years.

Endometrial biopsies were obtained, at all stages of the cycle, before treatment and thereafter during routine six-monthly examinations. The 137 biopsies studied were obtained at random from women taking the products being tested during a one-year period. The various products have been grouped according to endometrial effect and break-through bleeding incidence (Grant, 1967) as strongly progestogenic, strongly oestrogenic, and intermediate compounds. They have been further subdivided according to oestrogen content (Table III). The specimens were examined without previous knowledge of clinical details. Curetted fragments were frozen immediately after removal, and sections were prepared and examined as described by Southgate et al. (1967). Monoamine oxidase activity was demonstrated by the method of Glenner et al., 1957). Alkaline and acid phosphatase were demonstrated by an azo dye coupling method, Fast Red LTR (Pryse-Davies et al., 1961) being used.

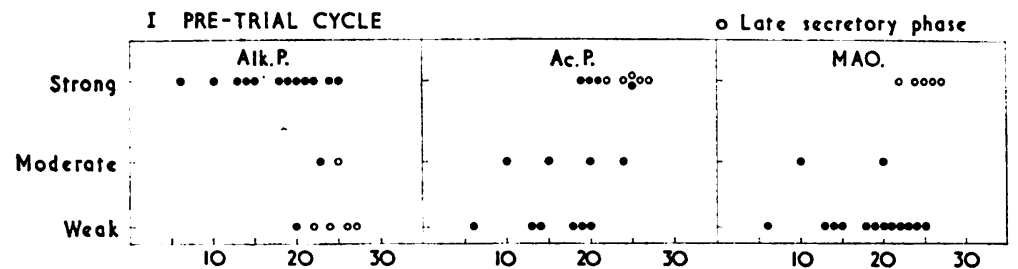

II STRONGLY PROGESTAGENIC COMBINED TABLETS (B.T.B. O-3\%)
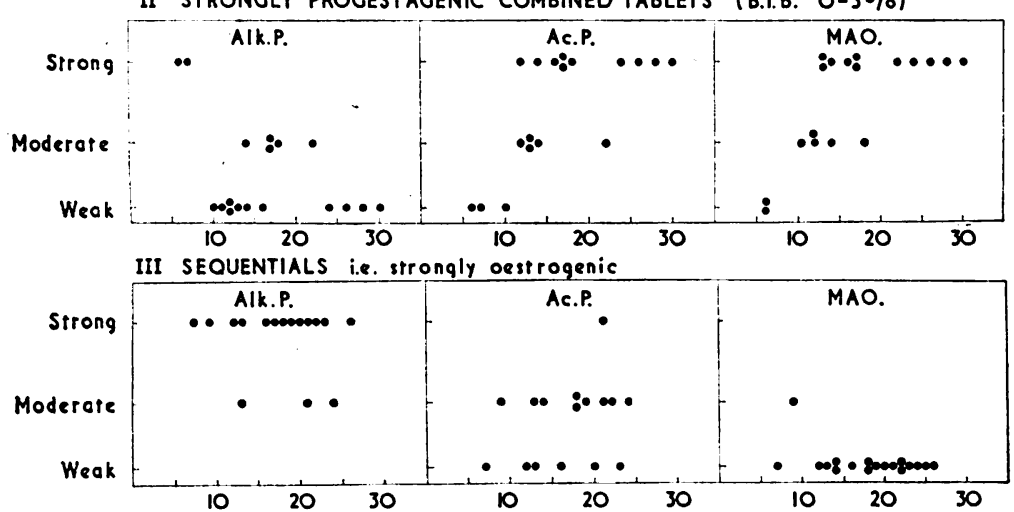

IV COMBINED TABLETS WITH E.O. (B.T.B. $4 \%$ or moIe)
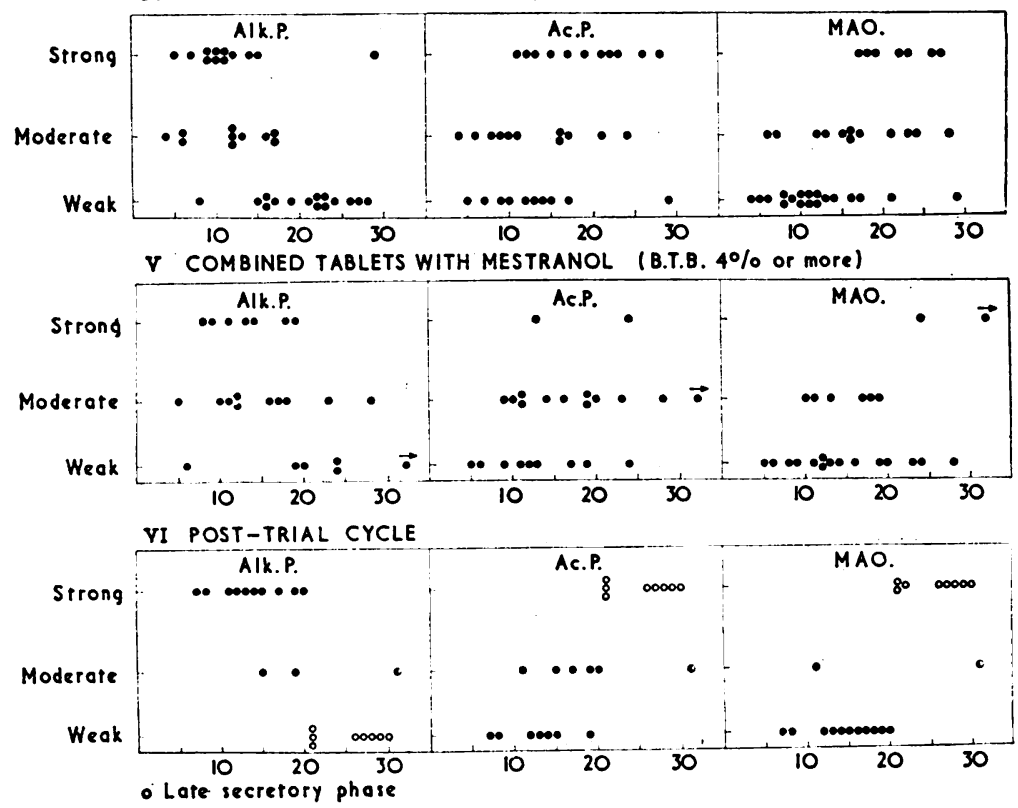

Graphs illustrating alkaline phosphatase, acid phosphatase, and monoamine oxidase activity in the menstrual cycles of untreated and oral-contraceptive-treated women.

\section{Clinical Results}

Tables I and II show the percentage of women complaining of depression and loss of libido on the individual preparations. These are grouped according to hormone balance and type of oestrogen in Table IV. The incidence of depression and loss of libido ranged from $28 \%$ of women on strongly progestogenic preparations containing ethinyloestradiol to $7 \%$ of women on the strongly oestrogenic sequential regimens containing ethinyloestradiol and $5 \%$ on the sequentials containing mestranol: these figures differ significantly $(P<0.01)$ from the average incidence of $16 \%$ for all women in Table IV. Thus the incidence of depression and loss of libido are greatest with the strongly progestogenic oral contraceptives containing a small dose of oestrogen. Two of the 136 women taking Anovlar (norethisterone acetate $4 \mathrm{mg}$. + ethinyloestradiol $0.05 \mathrm{mg}$.) became sufficiently depressed to attempt suicide. Though Lyndiol (lynoestrenol $5 \mathrm{mg}$. + mestranol $0.15 \mathrm{mg}$.) is strongly progestogenic (break-through bleeding $2 \%$ ) it also contains a high dose of mestranol and has a low incidence of depression and loss of libido, whereas Volidan (megestrol acetate $4 \mathrm{mg}$. + ethinyloestradiol $0.05 \mathrm{mg}$.) is less progestogenic (break-through bleeding $10 \%$ ) but contains a low dose of ethinyloestradiol and has a high incidence of depressive change.

Other mood changes noted were tiredness, irritability, aggression, and increased libido. These could not be related to hormone balance but may be influenced by vascular changes. Aggression was particularly noticeable with norethisterone acetate $1 \mathrm{mg}$. and ethinyloestradiol $0.075 \mathrm{mg}$., which had a marked effect on the development of both arterioles and sinusoids in the endometrium. Premenstrual tension, which was a common complaint before the trial, especially in older women, almost invariably improved. Only a few women discontinued the tablets because of mood changes in the early cycles, but over the period of the trial $40 \%$ of those withdrawing for side-effects had at least one mood complaint.

\section{Histochemical Results}

Fig. 1 shows the activities of the three enzymes according to the day of the cycle. In the untreated groups (I and VI) the late secretory phase is also indicated. 


\section{Untreated Cycle}

Alkaline phosphatase activity was strongest in the late proliferative phase in the glandular and superficial epithelium, decreased in the latter half of the cycle, and disappeared in the late secretory phase. Activity was considered strong when more than two-thirds of the epithelium showed activity, moderate when about half the epithelium stained, and weak when less than a third showed evidence of activity. Alkaline phos-

TABLE I.-Oral Contraceptive Compounds Containing Mestranol

\begin{tabular}{|c|c|c|c|c|c|c|}
\hline $\begin{array}{l}\text { Progestagen } \\
\text { (mg.) }\end{array}$ & $\begin{array}{l}\text { Mes- } \\
\text { tranol } \\
\text { (mg.) }\end{array}$ & $\begin{array}{l}\text { Trade } \\
\text { Name }\end{array}$ & $\begin{array}{l}\text { Women } \\
\text { Starting }\end{array}$ & Cycles & $\begin{array}{l}\text { B.T.B. } \\
\text { Cycles } \\
(\%)\end{array}$ & $\begin{array}{l}\text { Women with } \\
\text { Loss of } \\
\text { Libidc and } \\
\text { Depresinun } \\
(\%)\end{array}$ \\
\hline 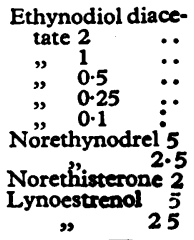 & \multirow[t]{2}{*}{$\begin{array}{l}0.1 \\
0.1 \\
0.1 \\
0.1 \\
0.1 \\
0.075 \\
0.1 \\
0.1 \\
0.15 \\
0.075\end{array}$} & \multirow[t]{2}{*}{$\begin{array}{l}\text { Metrulen } \\
\text { Ovulen } \\
\\
\text { Conovid } \\
\text { Conovid E } \\
\text { Orthunoum } \\
\text { Lyndiol } \\
\text { Lyndiol 2.5 }\end{array}$} & $\begin{array}{l}25 \\
30 \\
19 \\
25 \\
11 \\
27 \\
28 \\
55 \\
28 \\
34\end{array}$ & $\begin{array}{l}525 \\
629 \\
202 \\
287 \\
140 \\
515 \\
678 \\
965 \\
969 \\
576\end{array}$ & $\begin{array}{r}* 2 \\
4 \\
15 \\
40 \\
25 \\
16 \\
20 \\
* 2 \\
* 2 \\
4\end{array}$ & $\begin{array}{r}20 \\
13 \\
21 \\
8 \\
9 \\
22 \\
10 \\
20 \\
3 \\
26 \\
26\end{array}$ \\
\hline & & & 282 & 5483 & & \\
\hline
\end{tabular}

Sequential preparations :

Mestranol (mg.)

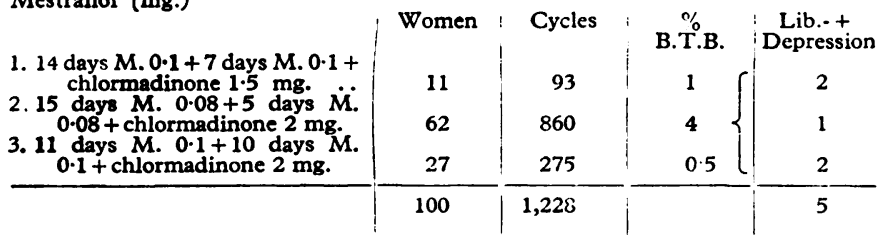
- Strongly progestogenic compounds, including Lyndiol, which is strongly

TABLE II.-Oral Contraceptive Compounds Containing Ethinyl

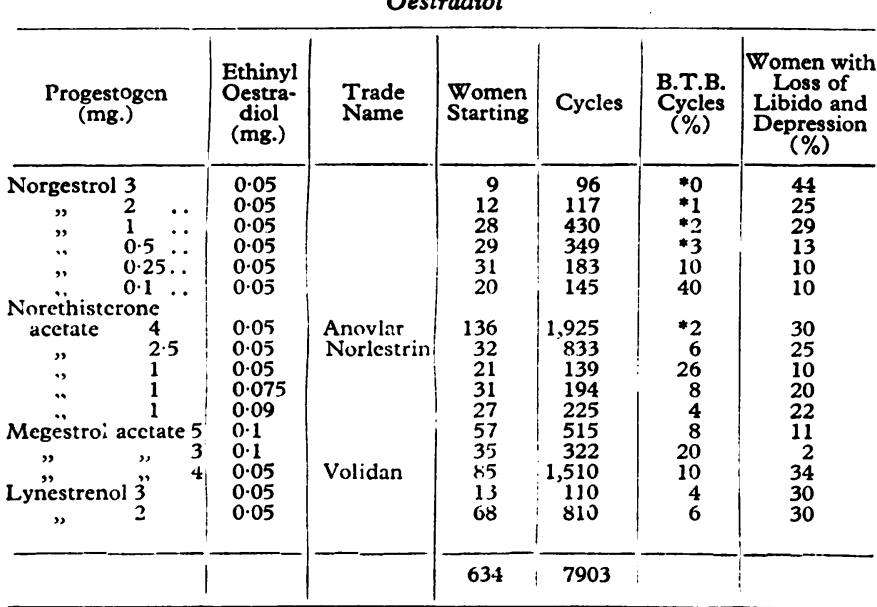

\begin{tabular}{|c|c|c|c|c|}
\hline Sequential preparations: & - Women & Cycles & & \\
\hline $\begin{array}{l}\text { 1. } 11 \text { days } E .0 .0 .05 \mathrm{mg}+10 \text { days } \\
\text { E.O. } 0.05 \text { mg. }+ \text { chlormadi- }\end{array}$ & \multirow[b]{2}{*}{24} & \multirow[b]{2}{*}{140} & \multirow[b]{2}{*}{5} & \\
\hline 2. 11 days $1 \mathrm{mg} .0 .0 .05 \mathrm{mg} .+10$ days & & & & 1 \\
\hline 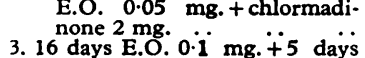 & 25 & 137 & 3 & 4 \\
\hline $\begin{array}{l}\text { E.O. } 0.1 \text { mg. }+ \text { megestrol } \\
\text { acetate } 5 \mathrm{mg} . \\
\text { 4. } 16 \text { days } E .0 .0 .075 \mathrm{mg} .+5 \text { days }\end{array}$ & 84 & 1.249 & 05 & 6 \\
\hline $\begin{array}{l}\text { E. } 0.05 \text { mg. }+ \text { megestrol ace- } \\
\text { tate } 4 \mathrm{mg} .\end{array}$ & 49 & 375 & 4 & 3 \\
\hline $\begin{array}{l}\text { 5. } 8 \text { days } \mathrm{E} .0 .0 .05 \mathrm{mg} .+12 \text { days } \\
\text { E.O. } 0.1 \mathrm{mg} \text {. }+5 \text { days E.O. } \\
0.15 \mathrm{mg}+5 \text { day medroxy- } \\
\text { progesterone acetate } 10 \text { mg. }\end{array}$ & & & & \\
\hline (Provera) $\quad . . \quad . . \quad$ & 19 & $17+$ & 0 & 0 \\
\hline & 201 & 2,275 & & 14 \\
\hline
\end{tabular}

- Compounds classified as strongly progestogenic.
TABLE III.-Number of Biopsies Obtained from Women in Various Groups

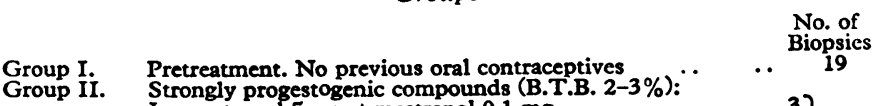
$\left.\begin{array}{llll}\text { Lynoestrenol } 5 \text { mg. + mestranol } 0.11 \text { mg. } & \because & \because & 3 \\ \text { Norgestrol } 1 \text { mg.+ +ethinylocstradiol } 0.05 \text { mg. } & \because & \because & 6 \\ \text { Norgestrol } 0.5 \text { mg. + ethinyloestradiol } 0.05 \text { mg. } & \because & 3\end{array}\right\} 19$

Group III. Norethisterone acetate $4 \mathrm{mg} .+$ ethinyloestradiol $0.05 \mathrm{mg}$.

Group III. Sequential formulations B.T.B. W S Weaker pro
4-26\%):

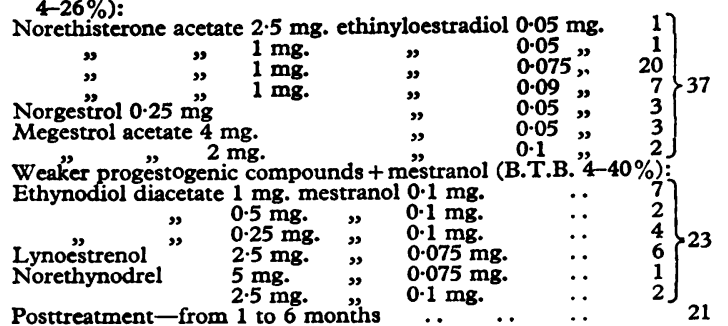

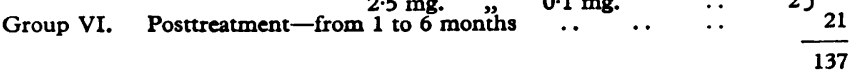 \\ Group V. Weaker prostranol (B.T.B. 4-40\%): Ethynodiol diacetate $1 \mathrm{mg}$. mestranol $0.1 \mathrm{mg}$.

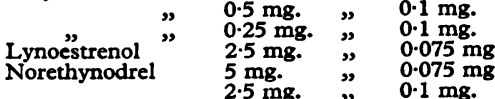

TABLE IV.-Percentage of Women with Mood Changes

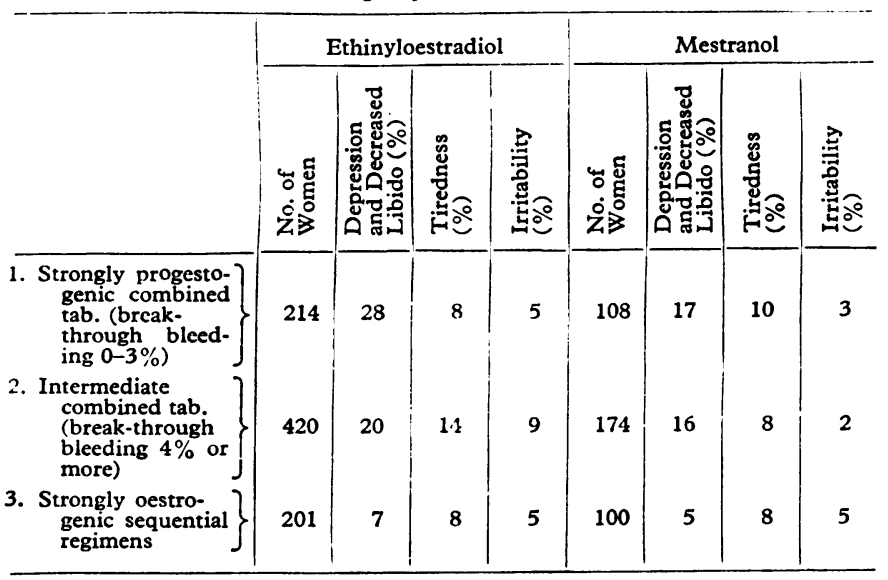

phatase was also seen in capillary and arteriolar endothelium throughout the cycle, but arteries showed little or no activity.

Acid phosphatase showed a more generalized activity in both epithelium and stroma. Early in the cycle there was weak staining of all elements, in mid-cycle staining became heavier in the epithelial cells, while in the later secretory phase there was a further increase of staining in the epithelium. These three degrees of activity were regarded as weak, moderate, and strong respectively.

Monoamine oxidase activity in the first half of the cycle was seen as dark granules or fine droplets scattered in the stroma and epithelium with no selective vascular staining. In the late secretory phase a purple-blue colour developed diffusely in the glandular epithelium, especially the luminal border. As a result of parallel biochemical studies by Southgate et al. (1967) it was found that the diffuse blue stain was associated with high monoamine oxidase activity in vitro and the granular stain with weak activity. Biopsies from 20 untreated and 24 treated patients in this series were also examined biochemically for monoamine oxidase activity; the results corresponded with the histochemical findings in each case, ranging from 1,000 to 20,000 units.

Enzyme activity in the cycles one month before and one to six months after treatment (Fig. 1, VI) was more closely related to the histological pattern than the exact day of the menstrual cycle. This accounts for the overlapping of results at 20 to 25 days, which depend on variations in time of ovulation. Flowers et al. (1966) found that while alkaline and acid phosphatase and diphosphopyridine nucleotide diaphorase enzyme activity was below normal in the second months after Ovulen 
therapy, normal activity was found during the third recovery month.

\section{Treated Cycles}

Grant (1967) described the histology of the normal and oral-contraceptive-treated endometrium.

Strongly Progestogenic Combined Tablets (Break-through Bleeding $0.3 \%$ ).- The high dose of progestogen allows only a short growth and early secretory phase from day 7 to 11 , which is followed by a prolonged post-secretory phase or atrophic phase, when the small glands have a single layer of low columnar cells. The enzyme pattern showed changes typical of a late secretory phase as early as day 12 (Fig. 1, II). Alkaline phosphatase was weak from day 10 and acid phosphatase strong from day 12. Monoamine oxidase was strong from day 12 even from very small fragments of atrophic endometrium. The overall incidence of depression and loss of libido on these preparations was $28 \%$ with ethinyloestradiol but only $17 \%$ when combined with larger doses of mestranol.

Sequential Tablets (Break-through Bleeding 0-5\%).-By contrast the strong oestrogen stimulation in the sequential regimens produces accentuated growth and early secretory phases and allows no definite secretory changes as late as day 26 (Fig. 1, III). There was a low monoamine oxidase level throughout the cycle. The incidence of depression and loss of libido on these preparations was $6 \%$.

Weakly Progestogenic Combined Tablets (Break-through Bleeding $4-40 \%)$.-These have more prolonged proliferative and early secretory phases, the length of the latter being proportional to the incidence of break-through bleeding. A tablet with a $4 \%$ incidence has a modified early secretory phase from days 8 to 12 , while one with $40 \%$ incidence of break-through bleeding may be secretory from days 10 to 20 .

(a) Containing 0.05-0.09 mg. Ethinyloestradiol: An intermediate picture was seen in this group with a gradual decrease in alkaline phosphatase and early increase in acid phosphatase activity (Fig. 1, IV). The post-secretory low columnar or cuboidal glands showed a weak, moderate, or strong monoamine oxidase activity from day 17 onwards.

(b) Containing 0.075-0.1 mg. Mestranol: Alkaline phosphatase was stronger and acid phosphatase weaker during the cycle than with the corresponding ethinyloestradiol tablets. Though most specimens were from Ovulen and Lyndiol 2.5 (break-through bleeding $4 \%$ ) which produce a post-secretory atrophic endometrium from day 13 onwards, only two biopsies showed a strong monoamine oxidase activity (Fig. 1, V). The day 24 specimen giving a strong reaction was from the Ovulentreated endometrium of a woman complaining of loss of libido. The other strong reaction was given after several months' continuous therapy with Lyndiol 2.5, when the patient was complaining of depression and abdominal distension: cyclic therapy, discontinued because of menstrual headaches, was then restarted at the patient's request.

\section{Discussion}

In the normal cycle there is a dramatic rise in the monoamine oxidase activity of the endometrium in the late secretory phase. At this time endogenous oestrogen levels fall and premenstrual tension is common, especially among older women. With a strongly progestogenic combined oral contraceptive tablet the rise in endometrial monoamine oxidase occurs early in the cycle at day 12 , at which time the woman is receiving constant amounts of exogenous oestrogen. If the amount of oestrogen is low some women may notice a depressant effect on mood or libido. Though a strongly progestogenic combined tablet such as Lyndiol has strong monoamine oxidase activity early in the cycle, the high dose of oestrogen in the tablet seems to protect against the depressant effect. However, Ferin (1966, personal communication) found that some ovariectomized women taking Lyndiol became depressed and treated them with monoamine oxidase inhibitors. With the strongly oestrogenic sequential regimens the amount of oestrogen is high, the monoamine oxidase activity low, and fewer women complain of depression. With the intermediate compounds monoamine oxidase varies in activity and may even be weak in post-secretory glands.

It is interesting, in view of our finding in women, that Michael et al. (1967) showed that progesterone inhibited sexual receptivity in female rhesus monkeys. As the endometrium is especially sensitive to variations in oestrogens and progestogens the changes in monoamine oxidase activity may reflect similar changes occurring in other sensitive areas of the body such as the hypothalamus. Cyclic changes in the rat hypothalamus have been reported by Kuwabara et al. (1967), who found that monoamine oxidase and biogenic amine activity reached a maximum at pro-oestrus. In women, plasma monoamine oxidase has been found to double at the end of the cycle, and significantly higher values were recorded in amenorrhoeic women (Klaiber et al., 1967). These findings support the hypothesis that progestogenic stimulation causes generalized changes in monoamine oxidase metabolism which may be a factor in the occurrence of depression and loss of libido in susceptible women.

Kane et al. (1967) described mood and behavioural disturbances in women who were using a variety of oral contraceptives, while Daly et al. (1967) reported iwo cases of psychosis associated with the use of sequential regimens. In our series many women had mood disturbances and vascular side-effects at the same time. It seems possible that susceptibility to mood changes may be affected by vascular reactivity (Grant, 1968).

We are grateful to Dr. Eleanor Mears and Dr. Hilary Hill for their interest and encouragement in this project, which was supported financially by the Council for the Investigation of Fertility Control and the Lalor Foundation. We should also like to acknowledge the help of Dr. Barbara Schooling and Sister Barbara Lamb, the technical assistance of Mr. Keith Napier, and the advice on statistical analysis of results by Mrs. Ann Davis.

\section{REFERENCES}

Cohen, S., Bitensky, L., Chayen, J., Cunningham, G. J., and Russell, J. K. (1964). Lancet, 2, 56.

Daly,, R. J., Kane. F. J., and Ewing, J. A. (1967). Lancet, 2, 444.

Flowers, C. E., Vorys, N.. Stevens, V., Miller, A. T., and Jensen, L. (1966). Amer. Y. Obstet. Gynec., 96, 784.

Glenner. G. G., Burtner, H. J., and Brown, G. W. (1957). 7. Histochem. Cytochem., 5, 591 .

Goldzieher, J W., Moses, L. E., and Ellis, L. T. (1962). F. Amer. med. Ass., $180,359$.

Grant, E. C. G. (1967). F. Obstet. Gynaec. Brit. Cwlth, 74, 908.

Grant, E. C. G. (1968). Brit. med. 3., 3, 402.

Kane, F. J., Daly, R. J., Ewing, J. A., and Keeler, M. H. (1967). Brit 7. Psychrat., 113, 265.

Klaiber, E. L. Kobayashi, Y., and Brooverman, D. M. (1967). 49th Meeting of the Endocrine Society, Miami Beach, Florida. (Abstract.)

Kuwabara, S., Russfield. A., Weisz, J., and Lloyd, C. W. (1967). 49th Meeting of the Fntocrine Society, Miami Beach, Florida. (Abstract.)

McKay, D. G., Hertig A. T., Bardawil, W. A., and Velardo, J. T. (1956). Obstet. and Gynec., 8, 22.

Mears, E., and Grant, E. C. G. (1962). Brit. med. 7., 2, 75.

Mishael, R. P., Saayman, G. S., and Zumpe, D. (1967). F. Endocr., 39, 309 .

Pryse-Davies, J., Dawson, I. M. P., and Snape, I. M. (1961). F. Path. Bact., 81, 197.

Pullen, D. (1962). Brit. med. F., 2, 1016.

Southgate, J., Grant, E. C. G., Pollard, W., Pryse-Davies, J., and Sandler, M. (1967). Biochem. Pharmacol., 17, 721. 